\title{
Ten-Year Trends in the Morbidity of Diabetes Mellitus and Antidiabetic Drug Utilization in Croatia: A Study Based on Routinely Collected Data
}

\author{
Renata Pavlov, ${ }^{1}$ Ivančica Topličan, ${ }^{2}$ and Mladenka Vrcić Keglevic ${ }^{3}$ \\ ${ }^{1}$ Family Practice "Dr. Renata Pavlov", Aleja lipa 2a, 10000 Zagreb, Croatia \\ ${ }^{2}$ Family Practice "Dr. Ivančica Topličan", Aleja lipa 2a, 10000 Zagreb, Croatia \\ ${ }^{3}$ Foundation for the Development of Family Medicine in Croatia, Cresnjevec 32, 10000 Zagreb, Croatia \\ Correspondence should be addressed to Renata Pavlov; renata.pavlov@zg.t-com.hr
}

Received 31 October 2015; Revised 19 May 2016; Accepted 24 May 2016

Academic Editor: Hakan Yaman

Copyright ( 2016 Renata Pavlov et al. This is an open access article distributed under the Creative Commons Attribution License, which permits unrestricted use, distribution, and reproduction in any medium, provided the original work is properly cited.

\begin{abstract}
Objectives. To investigate trends of diabetes mellitus (DM) morbidity and antidiabetic drug utilization in Croatian primary health care (PHC) from 2005 to 2014. Method. Routinely collected morbidity data from all PHC units, presented in Croatian healthstatistics yearbooks, were retrieved. Data on drug utilization were retrieved from the Annual Reports of the Croatian Agency for Medicinal Products and Medical Devices (ATC/DDD, antidiabetic, A10). Results. Total morbidity increased by $33.3 \%$ and DM increased by $65.6 \%$, mostly in patients over age 65 (from 50\% to 57\%). Estimated DM prevalence in adults increased from $3.9 \%$ to $6.4 \%$. Increased morbidity was followed by an even higher increase in drug utilization (120\%). Metformin was first, with a constant increase (from $18 \%$ to $39 \%$ ), followed by glimepiride, while glibenclamide use decreased. Total utilization of insulin increased even more, mostly for aspart (600\%) and newly introduced glargine and detemir, while human insulin usage sharply decreased. Spending also increased, mostly for aspart (from $21 \%$ to $61 \%$ of total). Conclusions. Increased DM is followed by a higher increase in antidiabetic drug utilization; this trend will continue in the future. In Croatian PHC, metformin has primacy along with insulin analogues.
\end{abstract}

\section{Introduction}

Diabetes mellitus (DM) is a multifactorial disease that occurs in genetically susceptible individuals under the influence of environmental factors. Disorders in insulin secretion or insulin action, or both, lead to hyperglycaemia. In addition to the consequences of abnormal glucose metabolism, DM usually leads to long-term complications such as cardiovascular, ocular, neurological, and renal complications. According to World Health Organization (WHO) data, an estimated 1.5 million deaths were directly caused by diabetes in 2012, mainly because of those complications [1]. In Croatia, with 4.28 million inhabitants, DM complications were the sixth leading cause of death in women and the eighth in men older than 65 years in 2010 [2]. In 2010 and 2011, DM with its complications was the fourth highest-ranking reason for the hospitalization of elderly men and the third highest for elderly women in Croatia [3]. According to the Global Burden of Disease project data, the disability-adjusted life-years related to DM increased by $20 \%$ in Croatia during the period of 1990 2010 [4].

This chronic illness requires continuing medical care, including investments in health care personnel and facilities, as well as in pharmaceutical supplies. According to International Diabetes Federation, the majority of countries spend between $5 \%$ and $20 \%$ of their total health expenditure on diabetes. This is a significant challenge for healthcare systems and an obstacle to sustainable economic development [5]. In Croatia, around $10 \%$ of the health budget is spent on DM; of this, $85.7 \%$ is for the hospital treatment of DM complications, $8.8 \%$ is for antidiabetic drugs, $3.5 \%$ is for diabetologist care, and $2.04 \%$ is for primary care. $6.2 \%$ of total drug utilization in Croatia is spent on antidiabetics [6]. 
From the patient's perspective, DM is a lifelong, 24hour-a-day condition. It is up to the person living with this condition to pay attention every day to eating, exercising, taking medication, testing glucose levels, and maintaining a normal body weight [7]. In addition to the deterioration in quality of life, indirect costs for patients and society are related to a decline in work productivity and losses due to absenteeism and early retirement $[8,9]$.

We did not find any published studies investigating the long-lasting morbidity trends of DM in Croatia, particularly concerning everyday practices and relating to the whole population. Therefore, this study was undertaken to determine the 10-year (2005-2014) morbidity trends of DM patients registered in primary health care (PHC) in Croatia and to determine the trends for antidiabetic drug utilization during that period of time.

\section{Method and Materials}

2.1. Study Design. This study was observational and retrospective, based on routinely collected data at the national level. We decided to use official national data because they were coming from everyday practices and they were related to the whole population. Every health care institution in Croatia is obliged to collect and refer to the Croatian National Institute of Public Health (CNIPH) the data on each patient visit to $\mathrm{PHC}$, specialist-consultants, or in-hospital discharge. Furthermore, routinely collected data are shown to be a reliable source of information reflecting the everyday realities of health service delivery $[10,11]$. In this study used morbidity data are related to the PHC level. PHC in Croatia is mostly based on family practice and paediatric services. Almost $100 \%$ of the population is registered with PHC; the adult population and school-age children are on family doctors' lists and the majority of pre-school-age children are on paediatricians' lists and the rest are on family doctors' lists, so the whole population is included in the study. The routinely collected data on antidiabetic drug utilization used in the study also came from all pharmacies (in-hospital and out-of-hospital) in Croatia, allowing a complete picture of antidiabetic drug utilization. Furthermore, only PHC doctors (family doctors and paediatricians) in Croatia are responsible for issuing drug prescriptions, including antidiabetics, which are reimbursed by the Croatian Health Insurance Fund (CHIF).

2.2. Morbidity Data. Morbidity data were obtained from the Croatian Health Service Yearbooks, which are publicly available at the website of the CNIPH [2]. Morbidity data from the yearbooks are based on the patients' records from all PHC practices around Croatia and since 2008 on patients' electronic records. The registration is based on the instructions for data registration and collection using WHO recommendation. According to those instructions, the first visit of a patient suffering from a chronic condition (such as $\mathrm{DM}$ ) in a calendar year is registered as a morbidity case only once, independent of how many times he/she visited PHC [12].
In Croatia, the International Classification of Diseases version X (ICD-X) is used to register morbidity. Endocrine diseases are registered under $\mathrm{E}$ diagnoses. However, not all $\mathrm{E}$ diagnoses are present within the yearbooks. Endocrine diseases are grouped into four broad categories: thyroid disease (E00-E07), diabetes mellitus (E10-E14), obesity (E65-E66), and other endocrine, nutritional, and metabolic diseases. Because of those broad diagnostic categories, it is not possible to obtain separate data on Type 1 and Type 2; therefore, we will be only using the term DM. Furthermore, morbidity data are presented according to age group: 0-6 years, 7-19 years, 20-64 years, and over 65 years. All data were collected exactly in the way they were presented in the yearbooks over a 10-year period from 2005 to 2014. We calculated in percentages the ratio of $\mathrm{E}$ diagnoses in total morbidity, the ratio of DM diagnoses (E10-E14) within total E diagnoses, and the ratio of DM in relation to age groups. Rates of increases and decreases during the 10-year period were also calculated. Because the registration is based on one principle diagnosis per patient per year and because the entire Croatian population is included, it is possible to estimate the incidence and prevalence of DM in Croatia from this data.

2.3. Drug Utilization Data. Drug utilization data were obtained from yearly reports that are publicly available on the website of the Croatian Agency for Medicinal Products and Medical Devices (HALMED) [13]. The data obtained from these reports are based on data from all pharmacies, inhospital and out-of-hospital, in Croatia. In the reports, utilization is presented according to both ATC/DDD methodology and financial indicators. The pharmaceutical utilization is presented in DDD per 1,000 inhabitants per day (DDD/TID) and spending is shown in the Croatian currency, kunas (December 2005 exchange rate: $1 \mathrm{EUR}=7.4$ kunas, December 2014 exchange rate: 1 EUR $=7.7$ kunas).

The following data were collected: total drug utilization and the utilization of antidiabetic drugs, including oral drugs and insulin listed under label A10 based on the ATC classification, for the period 2005-2014. We calculate in percentage the ratios of antidiabetic utilization within total drug utilization and the utilization of individual antidiabetics, for both, pharmaceutical usage (DDD/TID) and spending (in kunas). The ratios of increased/decreased antidiabetic utilization during the 10 -year period were also calculated. According to the reports, only $2.98 \%-3.70 \%$ of drug utilization originated from in-hospital pharmacies [13]; therefore, the collected data were mainly related to antidiabetic drugs prescribed by PHC doctors.

The epidemiological descriptive observational method, free from artificial manipulation of the study data, was used in the study [14]. The collected data were analysed using Microsoft Excel package. The results are presented in absolute numbers, frequency (in \%), and graphically, the trends are displayed as line charts.

\section{Results}

The results are presented in two parts: morbidity trends and antidiabetic drug utilization trends. 


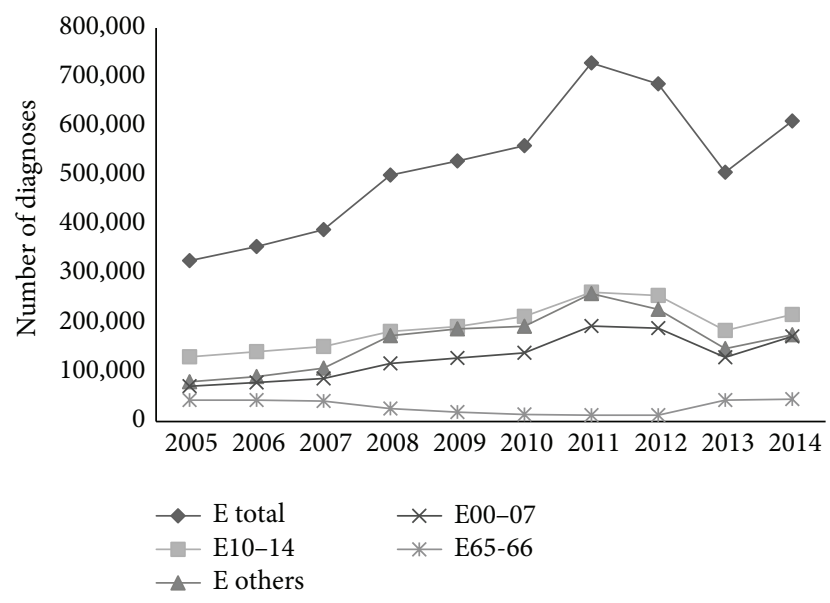

FIGURE 1: Trends in the number of endocrine diagnoses (E total; E00-E07, thyroid gland disorders; E10-E14, diabetes mellitus; E65E66, obesity; E others, other endocrine, nutritional, and metabolic disorders) registered in primary health care (family practice and paediatrics) in Croatia, 2005-2014.

3.1. Diabetes Mellitus Morbidity Trends. During the 10-year observational period, the total morbidity registered in Croatian $\mathrm{PHC}$ increased by $33.3 \%$. The percentage of all $\mathrm{E}$ diagnoses among total morbidity also increased, from $4.2 \%$ to $5.9 \%$. The total number of registered $\mathrm{E}$ diagnoses increased by $129 \%$ from 323,613 in 2005 to 742,195 in 2011 , when it was the highest, and then it decreased to 617,176 by 2014 . The highest increase of all of the $\mathrm{E}$ diagnoses was in the age group over 65 years $(87.3 \%)$. Among the $\mathrm{E}$ diagnoses, the most frequent was DM (E10-E14), with a decreased share from $40.1 \%$ in 2005 to $35.5 \%$ in 2014 . This was followed by the other endocrine, metabolic, and thyroid diseases. The lowest share belonged to obesity, which in some years was only $2 \%$ (2012). All of the diagnostic categories showed increases during the observation period, with thyroid gland disorders increasing by $140 \%$ and other endocrine and metabolic disorders by $118 \%$. Only obesity decreased, from 43,296 registered diagnoses in 2005 to 12,657 in 2011, and then steadily increased to 45,063 in 2014 (Figure 1).

During the observation period, the number of DM diagnoses registered in Croatian PHC increased by $65.6 \%$, from 131,154 diagnoses in 2005 to 217,170 in 2014. The diagnoses were mostly related to the adult populations and the larger portion $(50 \%-57 \%)$ belonged to patients over 65 years. In the age groups of 0-6 and 7-19 years, the shares decreased from $8.4 \%$ in 2005 to $5.9 \%$ in 2014 . The increase in 86,143 diagnoses over the 10-year period included approximately 8,614 newly diagnosed/registered DM patients per year in Croatian PHC (Figure 2). According to this figure, the observed incidence of DM in Croatia is around 20 patients per 1,000 inhabitants per year. The observed prevalence in the adult population (2011 Census: 3,388,284 individuals older than 20 years) increased from $3.9 \%$ to $6.4 \%$ during the 10 -year period. Furthermore, the increase was not equally distributed among the age groups, with the highest being the group over age 65 (87.3\%), followed by group $20-64$ years $(43.7 \%)$. The number of DM

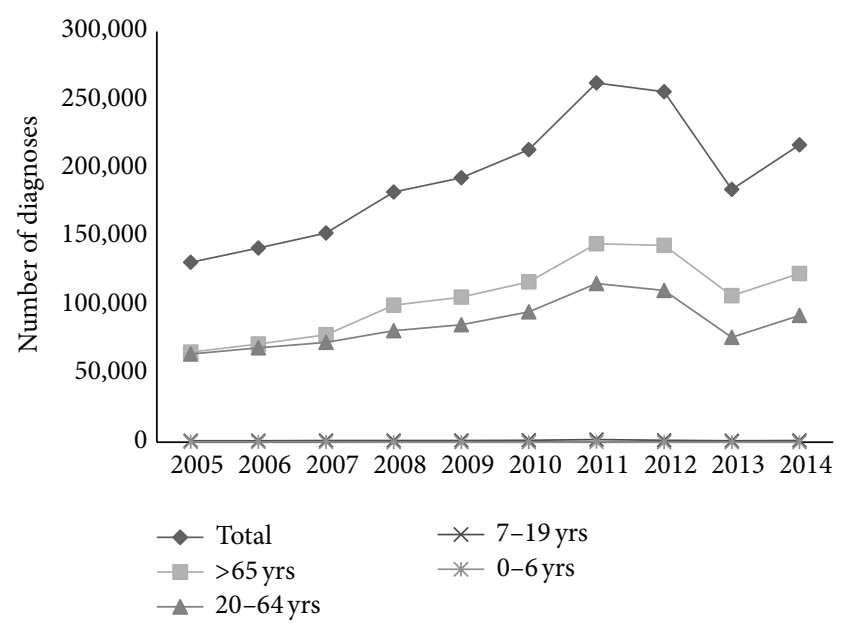

FIgURE 2: Trends in diabetes mellitus diagnoses registered in Croatian primary health care, family practice, and paediatrics, according to patient age, 2005-2014 (lines for the ages 0-6 and 719 years are overlapping).

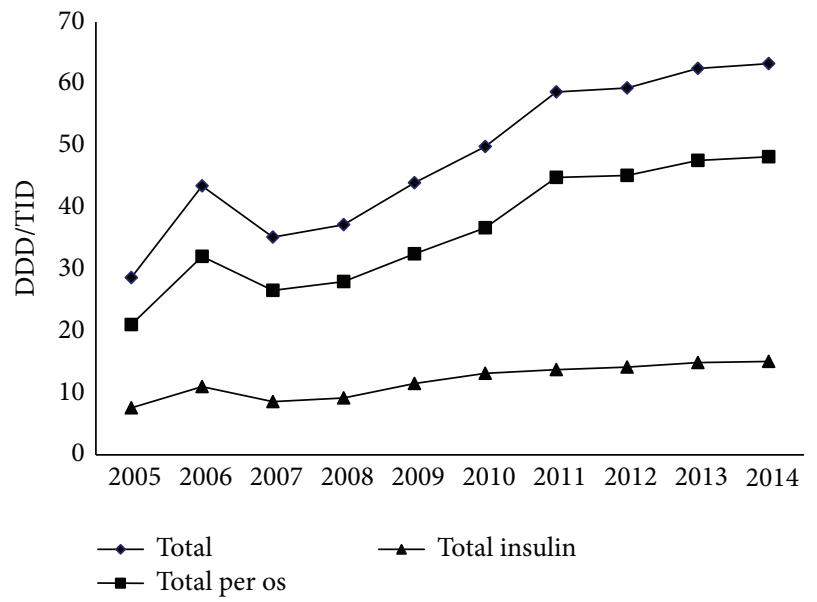

FIGURE 3: Trends in pharmaceutical consumption of antidiabetics (oral drugs and insulin) in DDD/TID in Croatia, 2005-2014.

diagnoses in the age groups of $0-6$ and 7-19 years was stable (in Figure 2 presented as overlapping lines).

3.2. Antidiabetic Drug Utilization. From 2005 to 2014, pharmaceutical utilization of all antidiabetics increased by $120 \%$, from $28.7 \%$ to $63.3 \% \mathrm{DDD} / \mathrm{TID}$. It occupied between $4.3 \%$ and $6.5 \%$ of total drug consumption in Croatia. The consumption of oral antidiabetics increased by $129 \%$ (from 21.07 DDD/TID in 2007 to 48.19 in 2014) and consumption of insulin increased by $99 \%$ (from 7.6 to $15.1 \mathrm{DDD} / \mathrm{TID}$ in 2014). More than $75 \%$ of total consumption was of oral antidiabetics and the shares were stable from 2007 to 2014. During the final four years, the increase was not as sharp (Figure 3).

Spending on all antidiabetics increased even more (147\%), from 128.3 million kunas in 2005 to 316.8 million kunas in 2014, which was $3.4 \%-5.8 \%$ of total spending on drugs in Croatia. Spending on insulin was more than that 


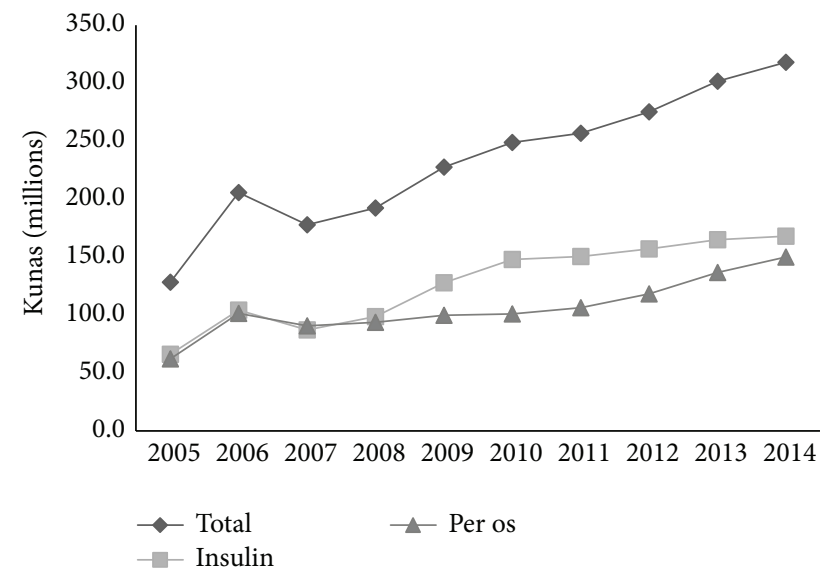

Figure 4: Trends in total spending (in millions of kunas) on antidiabetic drugs in Croatia, 2005-2014 (December 2005 exchange rate: $1 \mathrm{EUR}=7.4$ kunas, December 2014 exchange rate: $1 \mathrm{EUR}=7.7$ kunas).

for oral medications, with shares varying from $50 \%$ to $60 \%$. Furthermore, spending on insulin increased even more, by $153 \%$, from 66.1 million kunas in 2005 to 166.9 million kunas in 2014. Oral usage increased by $141 \%$, from 62.2 million kunas in 2005 to 149.9 in 2014 . The highest increase in oral drugs was during the final four years (Figure 4).

Among oral antidiabetic drugs, metformin was the most widely used, comprising between 25\% and 39.8\% (2013) of total antidiabetic drug utilization, with a constant increase during the follow-up period, especially after 2009, from 10.9 DDD/TID in 2009 to 18.9 DDD/TID in 2014 for a total increase of $73.4 \%$. Glimepiride was the second-ranked drug, with an even greater increase than metformin, from 3.4 DDD/TID in 2005 to $13.1 \mathrm{DDD} / \mathrm{TID}$ in 2014, for a total increase of $285 \%$. The utilization trends for repaglinide were stable, while the use of glibenclamide continuously decreased (84.4\%) from 5.2 DDD/TID in 2005 to $0.81 \mathrm{DDD} / \mathrm{TID}$ in 2014. Other antidiabetic drugs, such as dipeptidyl-peptidase 4 (DPP-4) inhibitors, alpha glucosidase inhibitors, and thiazolidinediones, were less utilized but with a constant increase (237.5\%) from 0.8 DDD/TID in 2005 to 2.7 in 2014. Among these, the largest increase was with DPP-4, introduced in Croatia in 2009. By 2014, its usage had increased $890 \%$ from 0.02 to $1.8 \mathrm{DDD} / \mathrm{TID}$ (Figure 5).

The total spending on all oral antidiabetics followed the trend of pharmaceutical utilization, sharply increasing from 2005 to 2006, after which some antidiabetics increased and others decreased. The highest increase (104\%) was observed in the drugs labelled "others," mostly newly introduced DPP4, and then metformin (96\%) and glimepiride (51\%). Again, the highest decreases were observed in glibenclamide $(78.7 \%)$ and repaglinide (59.7\%) (Figure 6).

Among all different kinds of insulin, the highest increase in pharmaceutical utilization was observed in aspart (600\%) from 1.4 DDD/TID in 2005 to $9.8 \mathrm{DDD} / \mathrm{TID}$ in 2014, accounting for approximately $65 \%$ of all kinds of insulin in 2014. Trends in the utilization of human insulin suddenly increased in 2005-2006 and then constantly decreased by

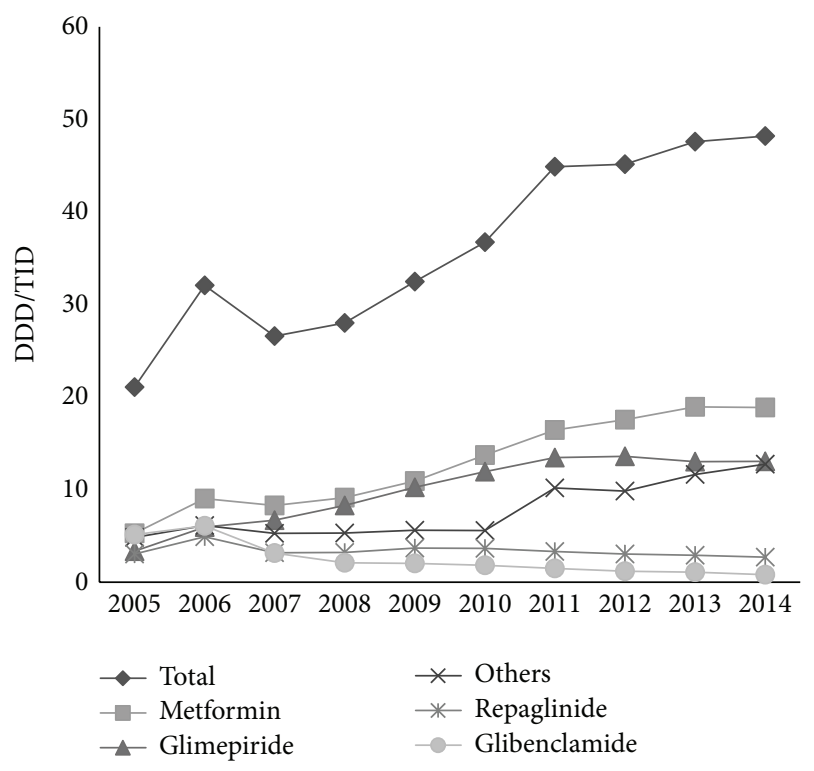

FIgURE 5: Trends in pharmaceutical utilization (in DDD/TID) of oral antidiabetic drugs in Croatia, 2005-2014.

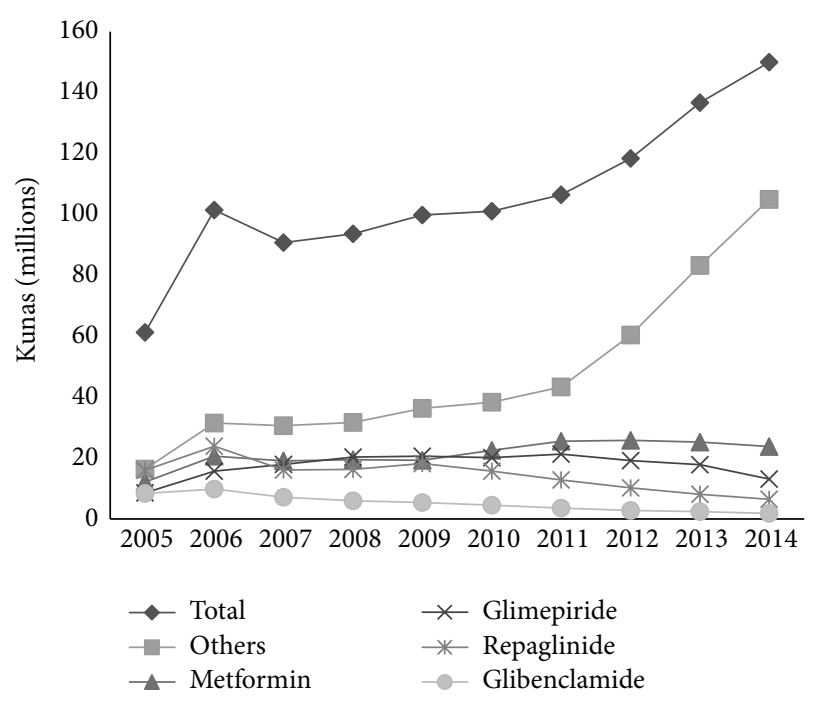

Figure 6: Trends in spending (in millions of kunas) for oral antidiabetic drugs in Croatia, 2005-2014.

$88 \%$ until the end of the observation period. In comparison to others, the utilization of glargine and detemir was relatively small, but with the greatest increases. Glargine increased by $1566 \%$ from 0.09 DDD/TID in 2005 to 1.5 DDD/TID in 2014 and detemir increased by 907\%, from 0.14 DDD/TID in 2006 to $1.41 \mathrm{DDD} / \mathrm{TID}$ in 2014 (Figure 7).

Following the pharmaceutical usage trend, the total spending on insulin rapidly increased as well, especially after 2008. The increase was from 66.1 million kunas in 2005 to 166.9 million kunas in 2014 , or $152 \%$. As with pharmaceutical utilization, the highest increase in spending was for aspart insulin, growing from $20.8 \%$ to $60.9 \%$ of total insulin costs with an increase from 13.8 million kunas in 2005 to 101.8 


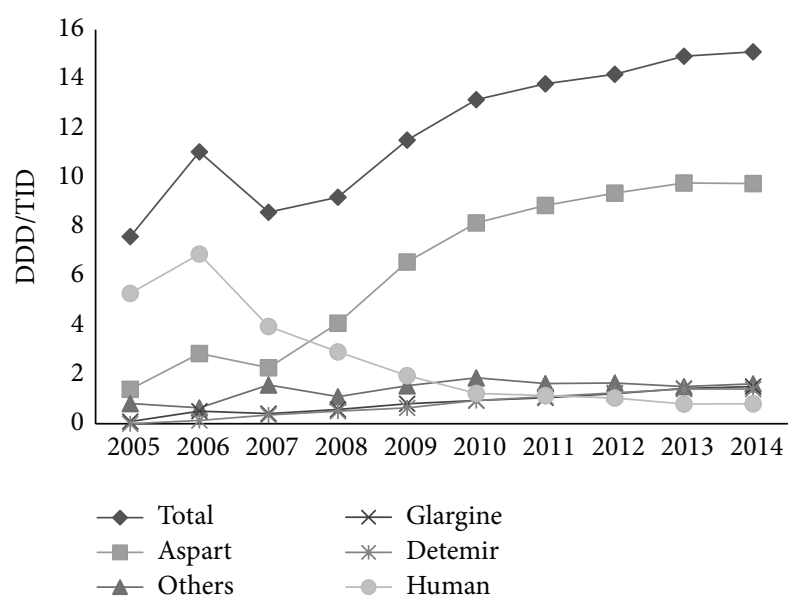

FIgURE 7: Trends in pharmaceutical utilization of insulin in DDD/TID in Croatia, 2005-2014.

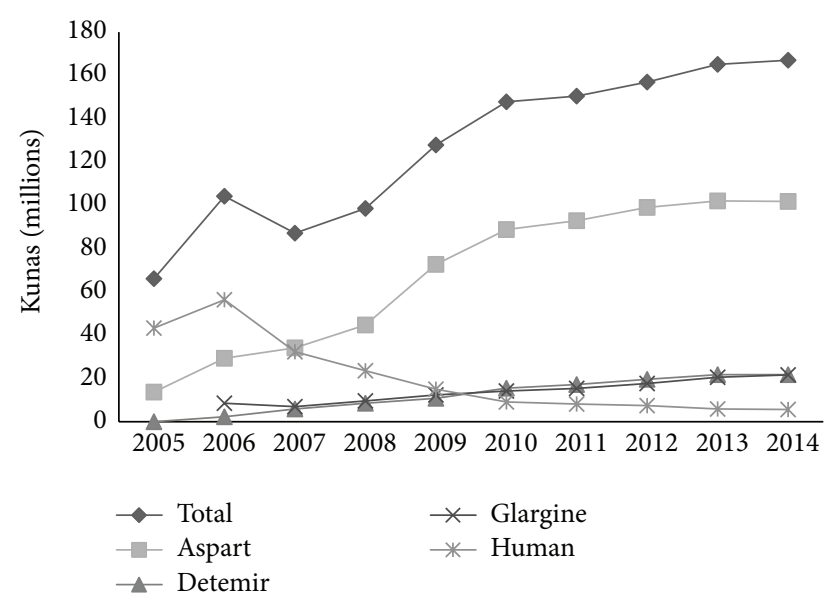

FIGURE 8: Trends in spending (in millions of kunas) on insulin in Croatia, 2005-2014.

million kunas in 2014. However, the increase in spending was higher than the increase in pharmaceutical utilization $(600 \%$ for pharmaceuticals and $638 \%$ for spending). The increased trends were also observed for glargine and detemir insulin. For glargine, the increase was from 1.6 million kunas in 2005 to 21.7 million kunas in 2014 , or $1256 \%$. For detemir, the increase was from 5.8 million kunas in 2007 to 21.8 million kunas in 2014 , or $276 \%$. The trend for human insulin showed a sudden increase from 43.2 million kunas in 2005 to 56.3 million kunas in 2006. After that time, the trend constantly decreased to 5.7 mil kunas in 2014, for a total decrease of $87 \%$. In 2014, total spending on insulin was 166.9 million kunas, with aspart accounting for $61 \%$, human insulin for $3 \%$, and glargine and detemir together for 26\% (Figure 8).

\section{Discussion}

4.1. Main Findings and Comparisons with Other Studies. The obtained results indicate that the total morbidity in Croatian PHC increased by $33.3 \%$ during the 10 -year observational period of 2005-2014. The total number of $\mathrm{E}$ diagnoses increased even more (129\%), and the increase in the number of DM diagnosis was $65.6 \%$. The largest portion of DM diagnoses belonged to patients over the age of 65 years $(50 \%-$ $57 \%$ ), and the increase was the highest in this age group. According to the results, the average observed incidence of DM was 20 patients per 1,000 inhabitants per year and the estimated prevalence in the Croatian adult population increased from $3.9 \%$ to $6.4 \%$ during the observed period. Although there is no real data on the prevalence of DM in Croatia, this is still lower than in other Croatian studies based on limited data sources; in the 18-65 age group, DM prevalence was estimated to be $6.1 \%$ [15] and in all adults it was estimated to be $8.9 \%$ [16], while in the elderly population it was $15 \%-20 \%$ [17]. Based on the present results, it can be said that a high probability of increased trends is expected in the future, with approximately 8,614 newly diagnosed/registered DM patients per year in Croatian PHC. It is obvious that the prevalence of DM will double in the next 10 years and the burden of DM will increase, possibly more than for other chronic diseases.

The obtained results are only partly comparable to those in the literature because of different research methodology. In 2010, according to the International Diabetes Federation (IDF), the global prevalence of DM was 6.6\%, and in European regions including Russia, DM prevalence is estimated to be $8.5 \%$ in the adult population [5]. Looking at the Southeast European Region Croatia belongs to, Turkey has the highest prevalence (14.8\%), followed by Montenegro (10.1\%), Macedonia (10.0\%), Serbia (9.9\%), and Bosnia and Herzegovina (9.7\%). According to the WHO and the IDF, the incidence of DM is increasing all over the world, particularly in low- and middle-income countries. The socially disadvantaged in any country are the most vulnerable to this disease $[1,5]$. Croatia is a middle-income country where the number of socially disadvantaged people is increasing, particularly during the current economic crisis.

Age is obviously an important risk factor for type 2 diabetes. We found that $50 \%-60 \%$ of DM diagnoses registered in $\mathrm{PHC}$ belonged to people aged over 65 years, while the share of this group in the total Croatian population in 2014 is $17.7 \%$. In the European region, $37 \%$ of the population is over 50 years old, and the most prominent factor in the raising trend of DM is attributed to the aging of populations in Germany, Spain, Italy, France, and the UK $[18,19]$. It is also obvious that obesity is an important risk factor $[19,20]$. It is surprising that the number of patients with obesity constantly decreased in our study. This could be more a matter of "forgotten" diagnoses in Croatian PHC than of reality, because several studies have demonstrated increases in overweight and obesity in the Croatian population $[21,22]$.

The rising trend of DM prevalence could also be related to the clinical guidelines, which have constantly lowered the diagnostic level for blood glucose. According to the 1985 WHO criteria, DM was diagnosed by a fasting blood glucose $(\mathrm{FBG})$ of $>7.8 \mathrm{mmol} / \mathrm{L}$ [23]. In the American Diabetes Association (ADA) criteria from 1997, the diagnostic level for fasting plasma glucose (FPG) was set at $>7.0 \mathrm{mmol} / \mathrm{L}$ [24], which was subsequently adopted by the WHO and by many 
nations, including Croatia [25]. The Croatian specificity is a mismatch of the diagnostic criteria (FBG $>7.0 \mathrm{mmol} / \mathrm{L}$ ) and the therapeutic target level of blood glucose (FBG > $6.6 \mathrm{mmol} / \mathrm{L}$ ) stated in the guidelines, which is often discussed among Croatian family doctors [25].

The situation with the diagnostic criteria for DM is even more complicated with regard to impaired fasting glycaemia and the diagnostic category of prediabetes [26, 27]. This phenomenon is often called overdiagnosis and overtreatment, as it unnecessarily labels a large number of people as ill, with no proven benefits [28-31]. According to small-scale research, the prevalence of impaired fasting glycaemia (by the WHO criteria) in Croatia is $11.3 \%$ [15]. We are not sure about the exact number of DM patients in this study to whom the diagnosis was established based on impaired fasting glycaemia and was labelled prediabetes. Furthermore, in Croatia, there is a lack of data on the number of reports of adverse reactions to statins, which are widely used, especially in diabetic patients [32-34]. The increase in HbAlc testing may also contribute to the rising DM prevalence, as was found in the USA [35]. During the last few years, HbAlc testing was introduced in Croatian PHC as a part of quality-improvement reimbursement schema, which could have some implications for the obtained results.

Increasing DM morbidity is followed by an even higher increase in antidiabetic drug utilization (morbidity increase, $65.6 \%$; drug utilization, $120 \%$ ). Metformin was the firstranking oral drug, with a constant increase during the follow-up period. The second-most used drug, glimepiride, increased even more, while glibenclamide usage constantly decreased. High increase was observed in the group named "others," mostly containing newly introduced DPP-4 inhibitors. Total utilization of insulin increased even more, mostly aspart and newly introduced glargine and detemir, while human insulin usage sharply decreased. Similar to the pharmaceutical trends, spending on antidiabetic drugs also increased because of the cost of insulin, mostly aspart, glargine, and detemir. However, the spending was not completely in line with pharmaceutical usage; spending on newly introduced drugs was much higher in comparison to their pharmaceutical consumption.

The increased metformin utilization was expected because this is in line with the Croatian guidelines of 2011 that suggested metformin as the first choice, similar to those stated at the ADA, EASD, National Institute for Health and Care Excellence, and other national guidelines [25, 36-40]. Comparable to our study, utilization of metformin has increased in all European countries [41, 42].

However, the finding in this study of the utilization of glimepiride as the second oral antidiabetic was somewhat unexpected, even more so if we consider a decrease in glibenclamide utilization. Sulfonylureas are usually added to metformin in many countries [39]. However, at this time there is no recommendation, or a consensus, on what the second-line drugs should be [43]. The reason for the frequent utilization of glimepiride in Croatia might be found in the Croatian, German, and NICE guidelines, which state that the combination of metformin with glibenclamide is associated with possibly unfavourable mortality data due to hypoglycaemia [38, 39]. There are several studies questioning the advantages and disadvantages of different sulfonilureas $[44,45]$. However, the newer studies and meta-analyses have shown that there is insufficient evidence that the combination of metformin and different sulfonilureas is connected with all-cause and specific cardiovascular mortality [46, 47]. There is also no evidence of significant differences in side effects, including hypoglycaemic effects [39]. We are also not sure if pharmaceutical marketing might have some influence on the utilization of glimepiride as the first choice among sulfonilureas in Croatia. This phenomenon should be clarified in future research, even more so if we consider the higher price of glimepiride versus glibenclamide and the limited financial resources within the Croatian healcare system.

A similar and somewhat unexpected situation was found in relation to the consumption of insulin. While the percentage of Croatian DM patients on insulin in our study (23\%) was similar to the UK (25\%) [41], the US (27.1\%) [48], and Portugal (20\%) [42] and was lower than in Sweden and Norway (both around 50\%) [42], the structures of insulin utilization are different. Contrary to other countries, the most often used one with the highest increase was aspart, while human insulin usage steadily decreased. This may relate to the Croatian guidelines, in which insulin analogues are given primacy [25]. According to the literature, despite some unimportant differences, human insulin are just as effective as the insulin analogues [49-52]. Based on this evidence, according to the NICE and many other guidelines, human insulin is recommended as the first-line insulin for treatment of type $2 \mathrm{DM}$ and also because of the costs [38, 53]. In our study, the majority of spending was for aspart, increasing from $20.8 \%$ to $60.9 \%$ of total insulin costs during the observation period.

4.2. Strengths and Weaknesses. The strength of this study comes from its 10-year follow-up period, a timeline that is long enough to allow the determination of existing trends and to forecast future trends regarding the prevalence of DM and antidiabetic drug utilization in Croatia. The 10-year observational period was chosen because that is long enough to ensure that every DM patient on PHC doctors' lists could be seen and registered. According to the literature, more than $95 \%$ of patients are seen by their PHC doctors within three consecutive years. In a 10 -year period, almost no DM patients would be missed [54]. Furthermore, the data come from the official national sources used for health-services planning in Croatia as well as for international comparisons. At the same time, the nature of the data was also a study limitation due to allowing the determination only of trends. Deeper insights, especially in terms of causal relationships in morbidity and antidiabetic drug utilization trends, are not possible in this type of research. The computerization of PHC and better registration, which started in 2005 and has been obligatory since 2008, might also have some influence on the increased number of DM diagnoses. In addition, the observed morbidity trends should not be mismatched with morbidity in theoretical meaning. As they mainly represent the reasons for patients visiting PHC, the trends in incidence 
and prevalence of DM are only estimations. Using routinely collected data does not allow us to make distinction between Type 1 and Type 2 DM, as well as between deferent age groups, which are also the study limitations. There is also some inconsistency with the morbidity data, for example, the sharp increase in the number of DM diagnoses in 2011 followed by decrease at the expected level, which could be attributed to the use of new computer software at that time. This should be taken into account in future data collections.

4.3. Implications for Practice. Beyond the limitations, the results of this study should be taken into consideration, firstly by PHC doctors, who should think about the scientific evidence and limited financial resources when working with diabetic patients. It will be also useful to think about introducing nonpharmacological measures for dealing with DM [55, 56]. It is even more important that, according the CroDiab 2012 data [57], only $26.9 \%$ of DM patients reached the targeted level of $\mathrm{HbAlc}$, despite the increase in antidiabetic drugs utilization. It might be also worthy to invest time and professional energy in the revision of the Croatian DM guidelines to bring them in line with the new scientific evidence and for exclusive use in PHC. Furthermore, the results are also important for diabetologists because of their specific roles within the Croatian health care system. Large numbers of DM patients are under the care of diabetologists in Croatia; until recently, family doctors and paediatricians were not even allowed to start insulin therapy before sending a patient for a diabetologist consultation, and insulin analogues could be prescribed and reimbursed by the CHIF only upon a dialectologist's recommendation. The obtained results could serve policy makers as the basis for health service planning, including human resources planning and defining boundaries between PHC and secondary care, but also to guide future trends in continuing professional development of PHC doctors. The results of this study also challenge future researchers to obtain answers on real DM and prediabetes morbidity in Croatia and to investigate the deeper causal relationships in antidiabetic drug utilization trends.

\section{Conclusions}

Routinely collected data show that the number of registered diagnoses of diabetes mellitus in Croatia is greatly increasing. It is obvious that this trend will continue in the future. The utilization of antidiabetics is also increasing, with some discrepancies between pharmaceutical usages and spending, pointing once again to the importance of the cost of drugs. As expected, metformin is used as the first-line choice, but glimepiride was second, giving it an importance that is not evidence-based or seen in other countries and guidelines. There is a similar situation with insulin, giving primacy to analogues in comparison to human insulin.

\section{Ethical Approval}

According to the Biomedical Research Ethics Committee System Act in Croatia, the present study based on publicly available data does not need ethical approval.

\section{Competing Interests}

The authors declare that there is no conflict of interests regarding the publication of this paper.

\section{Acknowledgments}

This study was supported by the Foundation for the Development of Family Medicine in Croatia.

\section{References}

[1] World Health Organization, World Health Day 2016: WHO calls for global action to halt rise in and improve care for people with diabetes, 2016, http://www.who.int/mediacentre/news/ releases/2016/world-health-day/en/.

[2] Croatian National Institute of Public Health, Croatian Health Service Yearbooks, 2005-2014, Croatian National Institute of Public Health, Zagreb, Croatia, 2006-2015, http://www.hzjz.hr/ publikacije/statisticki-ljetopis/.

[3] M. Vrcic Keglevic and K. Bonassin, "The incidence of 'ambulatory care sensitive conditions' (ACSC) in the hospital morbidity of people older than 65 years in the Republic of Croatia in the period from 2010 to 2011," in Proceedings of the XIII Congress, Croatian Society for Family Doctors, Croatian Medical Association, HDOD-HLZ, pp. 328-337, Rovinj, Croatia, 2013.

[4] Institute for Health Metrics and Evaluation (IHME), Global Burden of Disease Study 2010, Country profile-Croatia, IHME, Seattle, Wash, USA, 2010, http://www.healthdata.org/gbd.

[5] International Diabetes Federation Atlas, The Economic Impacts of Diabetes, IDF, Brussels, Belgium, 7th edition, 2015, http://www.diabetesatlas.org/.

[6] T. Poljicanin, The role of monitoring diabetic patients using the registry CroDiab to prevent complications [Ph.D. thesis], Faculty of Medicine Zagreb University, Zagreb, Croatia, 2010, http:// medlib.mef.hr/930/1/Poljicanin_T_disertacija_rep_930.pdf.

[7] M. M. Collins, C. P. Bradley, T. O'Sullivan, and I. J. Perry, "Self-care coping strategies in people with diabetes: a qualitative exploratory study," BMC Endocrine Disorders, vol. 9, article 6, 2009.

[8] K. Tunceli, C. J. Bradley, D. Nerenz, L. K. Williams, M. Pladevall, and J. E. Lafata, "The impact of diabetes on employment and work productivity," Diabetes Care, vol. 28, no. 11, pp. 2662-2667, 2005.

[9] American Diabetes Association, "Economic costs of diabetes in the U.S. in 2012," Diabetes Care, vol. 36, no. 4, pp. 1033-1046, 2013.

[10] S. de Lusignan and C. van Weel, "The use of routinely collected computer data for research in primary care: opportunities and challenges," Family Practice, vol. 23, no. 2, pp. 253-263, 2006.

[11] S. J. E. Barry, E. Dinnett, S. Kean, A. Gaw, and I. Ford, "Are routinely collected NHS administrative records suitable for endpoint identification in clinical trials? Evidence from the 
West of Scotland Coronary Prevention Study," PLoS ONE, vol. 8, no. 9, Article ID e75379, 2013.

[12] V. Desković-Vukres, M. Kuzman, U. Rodin, and R. Stevanovic, Instructions for Reporting Application Forms for Primary and Specialist Health Care, Croatian National Institute of Public Health, Zagreb, Croatia, 2nd edition, 1999, http://hzjz.hr/wpcontent/uploads/2013/11/upute_plava_knj.pdf.

[13] Croatian Agency for Medicinal Products and Medical Devices (HALMED), Yearly Reports, 2005-2014, Croatian Agency for Medicinal Products and Medical Devices (HALMED), Zagreb, Croatia, 2005-2014, http://www.halmed.hr.

[14] V. Babus, Epidemiological Methods, Medicinska naklada, Zagreb, Croatia, 2000.

[15] Z. Metelko, I. Pavlic-Renar, T. Poljicanin, L. Szirovitza, and S. Turek, "Prevalence of diabetes mellitus in Croatia," Diabetes Research and Clinical Practice, vol. 81, no. 2, pp. 263-267, 2008.

[16] T. Poljicanin and Z. Metelko, "Epidemiology of diabetes mellitus in Croatia and worldwide," Medix, vol. 15, no. 80-81, pp. 82-88, 2009.

[17] D. Vrdoljak and R. Pavlov, "Diabetes in elderly," Collegium Antropologicum, vol. 38, supplement 2, pp. 243-246, 2014.

[18] International Diabetes Federation, International Diabetes Federation Atlas, IDF, Brussels, Belgium, 6th edition, 2014, http://www.idf.org/sites/default/files/EN_6E_Atlas_Full_0.pdf.

[19] Health Intelligence, "Prevalence of Diabetes in the World, 2013," http://healthintelligence.drupalgardens.com/content/prevalence-diabetes-world-2013.

[20] N. Holman, N. G. Forouhi, E. Goyder, and S. H. Wild, "The Association of Public Health Observatories (APHO) diabetes prevalence model: estimates of total diabetes prevalence for England, 2010-2030," Diabetic Medicine, vol. 28, no. 5, pp. 575582, 2011.

[21] S. Music Milanovic, A. Ivicevic Uhernik, K. Fister, S. Mihel, A. Kovac, and D. Ivankovic, "Five-year cumulative incidence of obesity in adults in croatia: the crohort study," Collegium Antropologicum, vol. 36, supplement 1, pp. 211-216, 2012.

[22] I. Bralić, J. Vrdoljak, and V. Kovačić, "Associations between parental and child overweight and obesity," Collegium Antropologicum, vol. 29, no. 2, pp. 481-486, 2005.

[23] World Health Organization, Diabetes mellitus, Report of a WHO Study Group, World Health Organization, Technical Report Series 727, World Health Organization, Geneva, Switzerland, 1985, http://apps.who.int/iris/bitstream/10665/39592/1/WHO_ TRS_727.pdf.

[24] M. M. Gabir, R. L. Hanson, D. Dabelea et al., “The 1997 American diabetes association and 1999 world health organization criteria for hyperglycemia in the diagnosis and prediction of diabetes," Diabetes Care, vol. 23, no. 8, pp. 1108-1112, 2000.

[25] S. Kokic, M. Prasek, I. Pavlic-Renar et al., "Croatian guidelines for treatment of diabetes mellitus type 2," Medix, vol. 17, supplement 2, pp. 8-34, 2011, http://www.hljk.hr/Portals/0/ Medix\%20-\%20Suplement\%2008-34-smjernice-DM2.pdf.

[26] World Health Organization, "Definition and diagnosis of diabetes mellitus and intermediate hyperglycaemia," Report of a WHO Consultation, WHO, Geneva, Switzerland, 2006.

[27] The Expert Committee on the Diagnosis and Classification of Diabetes Mellitus, "Follow-up report on the diagnosis of diabetes mellitus," Diabetes Care, vol. 26, no. 11, pp. 3160-3167, 2003.

[28] K. Borch-Johnsen, S. Colagiuri, B. Balkau et al., "Creating a pandemic of prediabetes: the proposed new diagnostic criteria for impaired fasting glycaemia," Diabetologia, vol. 47, no. 8, pp. 1396-1402, 2004.

[29] R. P. Stolk, "Screening for diabetes," The British Medical Journal, vol. 335, no. 7618, pp. 457-458, 2007.

[30] J. S. Yudkin and V. M. Montori, "The epidemic of pre-diabetes: the medicine and the politics," British Medical Journal, vol. 349, Article ID g4485, 2014.

[31] P. Ghody, D. Shikha, J. Karam, and G. Bahtiyar, "Identifying prediabetes-is it beneficial in the long run?" Maturitas, vol. 81, no. 2, pp. 282-286, 2015.

[32] A. A. Carter, T. Gomes, X. Camacho, D. N. Juurlink, B. R. Shah, and M. M. Mamdani, "Risk of incident diabetes among patients treated with statins: population based study," British Medical Journal, vol. 346, no. 7911, Article ID f2610, 2013.

[33] S. Mayor, "Statins associated with $46 \%$ rise in type 2 diabetes risk, study shows," British Medical Journal, vol. 350, Article ID h1222, 2015.

[34] Z. Vojvodić and D. Stimac, "Trends in statin consumption and cardiovascular mortality in Croatia 2004-2012," Collegium Antropologicum, vol. 38, supplement 2, pp. 73-78, 2014.

[35] G. A. Nichols, E. B. Schroeder, A. J. Karter et al., "Trends in diabetes incidence among 7 million insured adults, 2006-2011, the SUPREME-DM project," American Journal of Epidemiology, vol. 181, no. 1, pp. 32-39, 2015.

[36] American Diabetes Association, "Standards of medical care in diabetes-2014," Diabetes Care, vol. 37, supplement 1, pp. S14S80, 2014.

[37] S. E. Inzucchi, R. M. Bergenstal, J. B. Buse et al., "Management of hyperglycaemia in type 2 diabetes: a patient-centered approach. Position statement of the american diabetes association (ADA) and the european association for the study of diabetes (EASD)," Diabetologia, vol. 55, no. 6, pp. 1577-1596, 2012.

[38] National Institute for Health and Care Excellence NICE (NG28), "Type 2 diabetes in adults: management," 2015, https://www.nice.org.uk/guidance/ng28/chapter/1-Recommendations\#blood-glucose-management- 2 .

[39] W. A. Scherbaum and T. Haak, "Medical antihyperglycaemic treatment of diabetes mellitus type 2," EvidenceBased Guideline of the German Diabetes Association (DDG), Update from October 2008, Düsseldorf, Germany, 2008, http://www.hlz.hr/smjernice/HDDijabetes.pdf.

[40] R. Boussageon, I. Supper, T. Bejan-Angoulvant et al., "Reappraisal of metformin efficacy in the treatment of type 2 diabetes: a meta-analysis of randomised controlled trials," PLoS Medicine, vol. 9, no. 4, Article ID e1001204, 2012.

[41] A. Melander, P. Folino-Gallo, T. Walley et al., "Utilisation of antihyperglycaemic drugs in ten European countries: different developments and different levels," Diabetologia, vol. 49, no. 9, pp. 2024-2029, 2006.

[42] H. Patel, J. Srishanmuganathan, J. Car, and A. Majeed, “Trends in the prescription and cost of diabetic medications and monitoring equipment in England 1991-2004," Journal of Public Health, vol. 29, no. 1, pp. 48-52, 2007.

[43] B. McIntosh, C. Cameron, S. R. Singh et al., "Second-line therapy in patients with type 2 diabetes inadequately controlled with metformin monotherapy: a systematic review and mixedtreatment comparison meta-analysis," Open Medicine, vol. 5, no. 1, pp. e35-e48, 2011.

[44] K. M. Pantalone, M. W. Kattan, C. Yu et al., "Increase in overall mortality risk in patients with type 2 diabetes receiving glipizide, glyburide or glimepiride monotherapy versus metformin: 
a retrospective analysis," Diabetes, Obesity \& Metabolism, vol. 14, no. 9, pp. 803-809, 2012.

[45] M. González-Ortiz, J. F. Guerrero-Romero, R. Violante-Ortiz et al., "Efficacy of glimepiride/metformin combination versus glibenclamide/metformin in patients with uncontrolled type 2 diabetes mellitus," Journal of Diabetes and its Complications, vol. 23, no. 6, pp. 376-379, 2009.

[46] A. D. Rao, N. Kuhadiya, K. Reynolds, and V. A. Fonseca, "Is the combination of sulfonylureas and metformin associated with an increased risk of cardiovascular disease or all-cause mortality?" Diabetes Care, vol. 31, no. 8, pp. 1672-1678, 2008.

[47] W. T. Cefalu, J. B. Buse, S. Del Prato et al., "Beyond metformin: safety considerations in the decision-making process for selecting a second medication for type 2 diabetes management: reflections from a diabetes care editors' expert forum," Diabetes Care, vol. 37, no. 9, pp. 2647-2659, 2014.

[48] C. Hampp, V. Borders-Hemphill, D. G. Moeny, and D. K. Wysowski, "Use of anti-diabetic drugs in the U.S., 2003-2012," Diabetes Care, vol. 37, no. 5, pp. 1367-1374, 2014.

[49] N. Waugh, E. Cummins, P. Royle et al., "Newer agents for blood glucose control in type 2 diabetes: systematic review and economic evaluation," Health Technology Assessment, vol. 15, supplement 1, pp. 77-86, 2011.

[50] M. B. Davidson, "Insulin analogs-is there a compelling case to use them? No!,” Diabetes Care, vol. 37, no. 6, pp. 1771-1774, 2014.

[51] W. Rathmann, N. C. Schloot, K. Kostev, M. Reaney, A. J. Zagar, and A. Haupt, "Macro- and microvascular outcomes in patients with type 2 diabetes treated with rapid-acting insulin analogues or human regular insulin: a retrospective database analysis," Experimental and Clinical Endocrinology and Diabetes, vol. 122, no. 2, pp. 92-99, 2014.

[52] K. Horvath, K. Jeitler, A. Berghold et al., "Long-acting insulin analogues versus NPH insulin (human isophane insulin) for type 2 diabetes mellitus," Cochrane Database of Systematic Reviews, no. 2, Article ID CD005613, 2007.

[53] I. Idris, J. Gordon, C. Tilling, and J. Vora, "A cost comparison of long-acting insulin analogs vs NPH insulin-based treatment in patients with type 2 diabetes using routinely collected primary care data from the UK," Journal of Medical Economics, vol. 18, no. 4, pp. 273-282, 2015.

[54] V. F. A. Van Casteren, N. H. E. Bossuyt, S. J. S. Moreels et al., "Does the Belgian diabetes type 2 care trajectory improve quality of care for diabetes patients?" Archives of Public Health, vol. 73, no. 1, article 31, 2015.

[55] L. Avery, D. Flynn, S. U. Dombrowski, A. van Wersch, F. F. Sniehotta, and M. I. Trenell, "Successful behavioural strategies to increase physical activity and improve glucose control in adults with Type 2 diabetes," Diabetic Medicine, vol. 32, no. 8, pp. 1058-1062, 2015.

[56] N. Garrett, C. M. Hageman, S. D. Sibley et al., "The effectiveness of an interactive small group diabetes intervention in improving knowledge, feeling of control, and behavior," Health Promotion Practice, vol. 6, no. 3, pp. 320-328, 2005.

[57] National Diabetes Registry CroDiab, Annual Report for 2012, Croatian National Institute of Public Health, Zagreb, Croatia, 2013, http://www.hzjz.hr/wp-content/uploads/2013/11/ crodiabreg2012.pdf. 


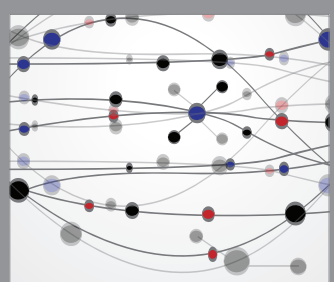

The Scientific World Journal
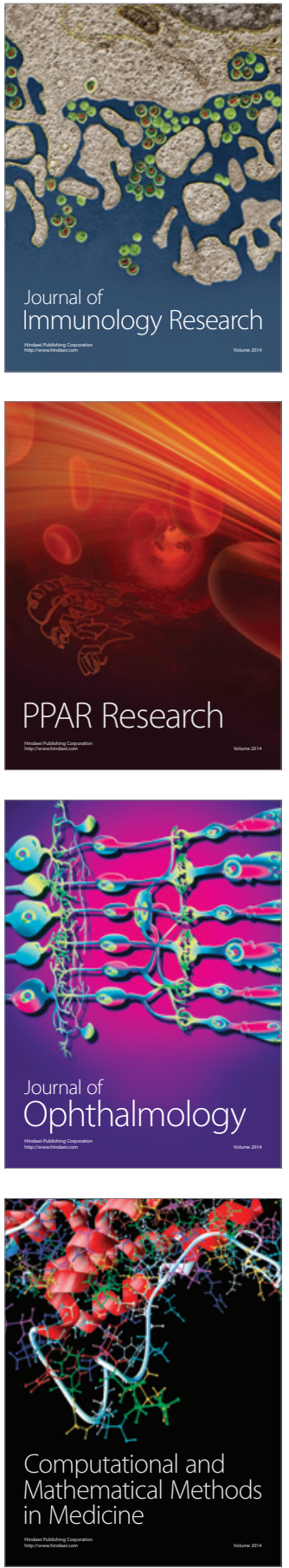

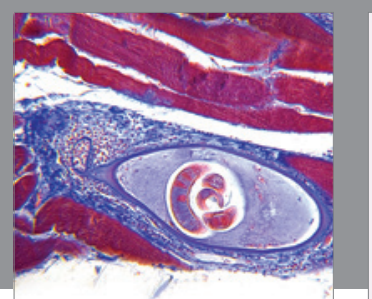

Gastroenterology Research and Practice

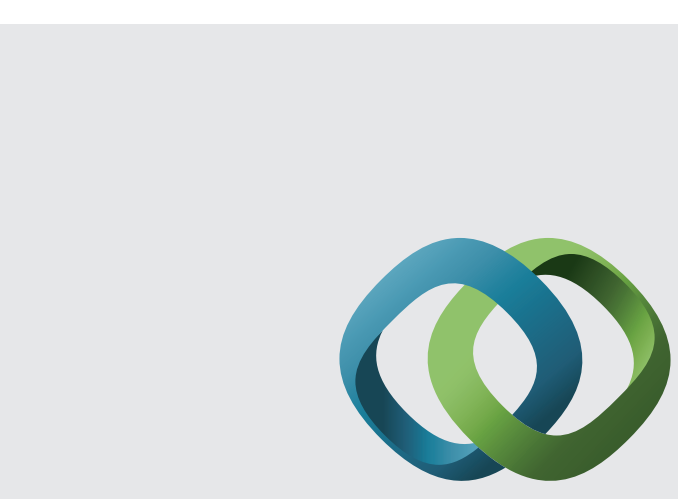

\section{Hindawi}

Submit your manuscripts at

http://www.hindawi.com
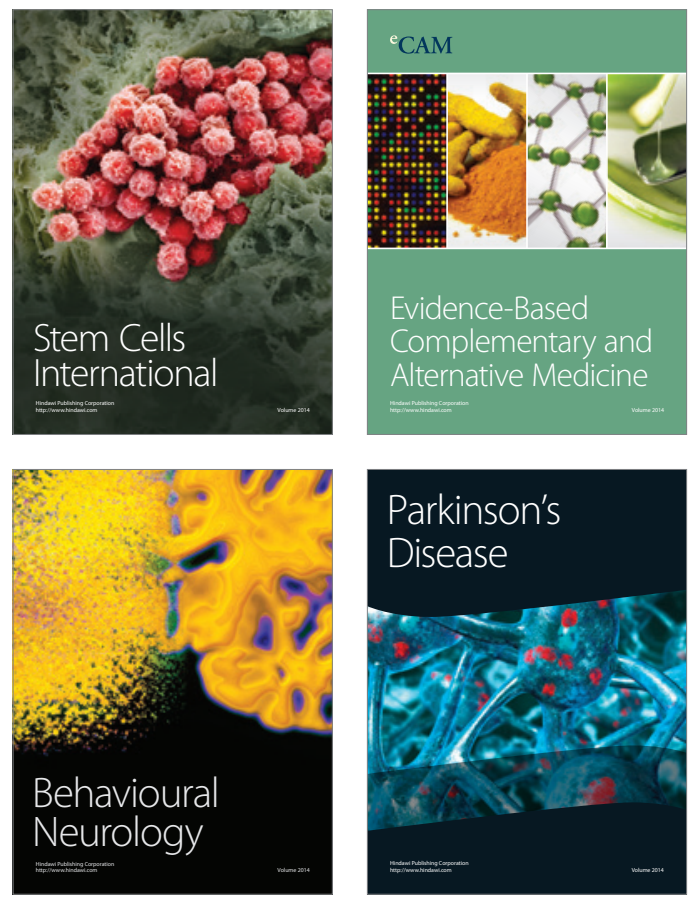
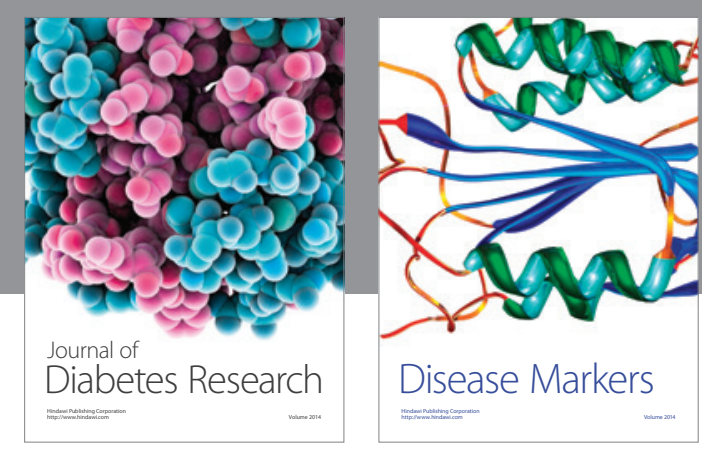

Disease Markers
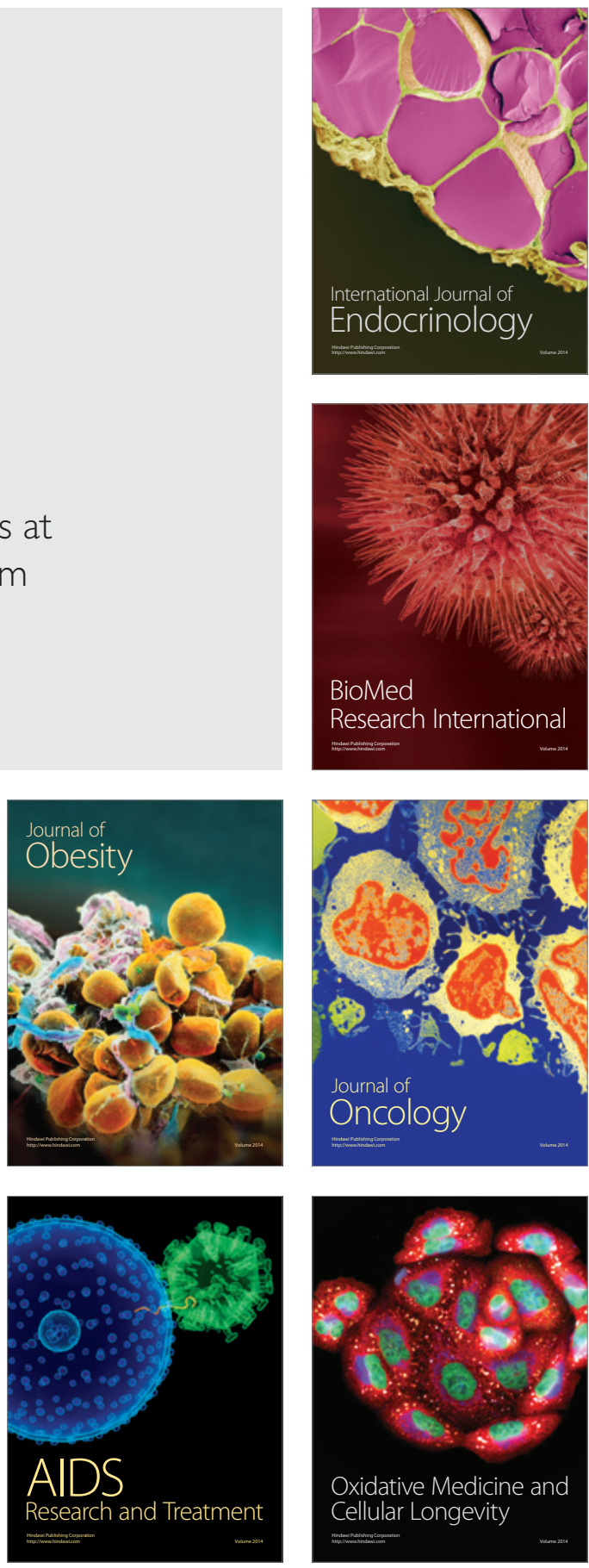